\title{
A computational analysis of the scarf angle on a composites repair
}

\author{
Yun-Hae Kim ${ }^{1 *}$, Young-Dae $\mathrm{Jo}^{1}$ and Ri-ichi Murakami ${ }^{2}$ \\ ${ }^{1}$ Division of Marine Equipment Engineering, Korea Maritime University, Busan 606 -791, Korea \\ ${ }^{2}$ Department of Mechanical Engineering, The University of Tokushima, 2-1, Minamijosanjima-cho, Tokushima, Japan
}

(Manuscript Received December 9, 2010; Revised January 14, 2011; Accepted January 29, 2011)

\begin{abstract}
This study examined the relationship between the scarf angle and stress distribution, and estimated the strength recovery via a finite element analysis. The following conclusions were drawn from this study. Resin will fracture due to a tensile load with a high scarf angle, which is similar to the patch repair method. An applied stress can be loaded to a repaired laminate if the scarf angle is $5^{\circ}$. The Von-Mises stress increases with decreasing scarf angle, with the exception of a scarf angle of $30^{\circ}$, where the scarf angle can indicate the rates of shear and normal stresses. Strength recovery can be better if the scarf angle is decreased to a lower angle. However, scarf machining requires more time, a high skill level and considerable expense. Therefore, a scarf angle of $5^{\circ}$ is the most effective for a repair. These results may provide a guide for engineers wishing to formulate a standard for repair. The scarf angle needs to be carefully managed for a more efficient composite repair.
\end{abstract}

Keywords: Composite repair, Finite element method, Scarf angle, Strength recovery, Sliding mode control

\section{Introduction}

Composites are made from a combination of two or more different materials and are designed for advanced applications. They differ from alloy metals in that the original phase of the material remains unchanged. Composites consist of a matrix and reinforcement, and are classified as FRM(Fiber Reinforced Metals), FRC(Fiber Reinforced Ceramics), and FRP(Fiber Reinforced Plastics). Generally, composites are fiber reinforced plastics, which are used in aerospace and automotive applications as well as for general machinery.

Composites are famous for their high specific strength, specific modulus, and damping characteristics.[1] They are generally used for structural materials, often in applications that require light weight properties, such as aircraft. For example, the A350 from Airbus and B787 from Boeing are

\footnotetext{
* Corresponding author. Tel.: +82-51-410-4355, Fax.: +82-51-410-4355. E-mail address:yunheak@hhu.ac.kr.

Copyright (C) KSOE 2011.
}

comprised of composites, which account for more than $50 \%$ of their total weights.[2] In the case of automotive applications, composites are used in F1 racing machines, such as Ferrari, Lamborghini and Aston Martin, as well as in many high performance sports cars. These cars use the monocoque system, and the body panels are made from composites, therefore, the use of composites improves the performance of vehicles. F1 racing cars are made from almost $90 \%$ composite materials, making the total weight of these machines only $620 \mathrm{~kg}$.[3]

Composites are used in many applications, but the possibility of accidents can severely damage these composites. There are many causes of damage to composites; accidents during operation, ground accidents and tooling damage, etc.. The repair of composites is more difficult than with conventional metal materials, such as aluminum and steel. In addition, the repair of composites is very expensive. For these reasons, many engineers and scientists have examined the methods for the repair of composites, 
but these studies have been limited to aerospace applications. Other industries, such as transportation, wind turbines and general industry demand guidelines for the repair of composites. The products already applied will age; hence, their repair and maintenance will be required to prevent catastrophic failure. Therefore, studies on the repair of composites are needed.

Several studies have examined methods of repair for composites, but these have not focused on the details of the repair process. The repair of composites is a type of bonding process, for example between the undamaged mother material and a newly prepared laminate or prepreg is one method. The bonding property of adhesive materials, surface conditions, layup method for repair and thickness of the patch, etc., can affect the repair results. In this study, the finite element method was used to examine the strength distribution on the repaired area and search for the relationships between the scarf angle and strength recovery, step distance and strength recovery. The aim of this study was to define the optimized repair conditions from the scarf angle and step distance. The properties of the adhesive material, layup method and other conditions were kept constant. This study provides guides for scarf machining and step distance for a repair layup method, which can be used to establish repair guide-lines for trains, automotives, wind turbine blades and other applications.

Table 1. Examples of damage

\begin{tabular}{c|c}
\hline \hline External damage & Internal damage \\
\hline Scratch & Delamination \\
Dent & Core crush \\
Edge crush & Moisture absorption \\
Punctures and gouges & Corrosion \\
Skin crack & \\
\hline
\end{tabular}

\section{Damage and repair method}

\subsection{Damage}

Composites can be damaged due to a range of causes, such as accidents, impact with flying objects, thunder, lightning, erosion and tooling damage. Damage to composites is classified as either internal or external damage. Composites are layered material, so invisible internal damage can cause a sudden accident.[4]

\subsection{Repair method}

Three methods can be used to repair composites; patch repair method, scarf sanding repair method and step sanding repair method. Generally, composites are fiber reinforced materials, so the continuity of the reinforcement fiber is important for strength. The surface of the repair can be a notch if the continuity is not recovered.

The patch repair method is the simplest repair method. The damaged area is extracted, filled with repair plies and overlapped with extra structural plies. A patch repair does not require an experienced technician and does not take much time. However, the patch repair method cannot be used for structural parts because the discontinuity of the repaired area will still remain. This discontinuity can be a notch in the repaired part.

The scarf sanding repair method allows better strength recovery than the patch repair method because the discontinuity is widely distributed. A scarf sanding repair is different from a patch repair in that the extracted edge is machined as a scarf. Repair plies and extra structural plies are the same as with the patch repair method. Scarf sanding repairs afford good strength recovery, and a clean surface compared to the patch repair method. In addition, this method does not required considerable time or a highly trained technician compared to the step sanding repair method. The disadvantages of scarf sanding repair are the difficult repair process, and greater amount of time compared to the patch repair method.

The step sanding repair method is the most difficult, but most effective repair method. All the layers are machined as a step. Prepregs are not thick materials therefore, Therefore, the step sanding repair method requires a highly trained technician and considerable time. However, a step sanding repair can achieve the most effective strength recovery.

\section{Influence of the scarf angle}

The scarf sanding repair method is the most effective repair method, is applied to the thick structure of aircraft [5] and it is quite useful for a wide repair of thin components because the repaired surface is very clean[6]. Scarf sanding repair is a very useful repair method for recovering the strength to that of the design strength. 
Table 2. Shows the mechanical properties of materials used for finite element analysis

\begin{tabular}{c|c|c}
\hline \hline & Glass/Epoxy & Adhesive \\
\hline Young's modulus (Pa) & $3.65+\mathrm{E} 10$ & $2.76+\mathrm{E} 9$ \\
Poisson's ratio & 0.3 & 0.42 \\
Ultimate tensile strength (Pa) & $7.91+\mathrm{E} 8$ & $8.00+\mathrm{E} 7$ \\
\hline
\end{tabular}

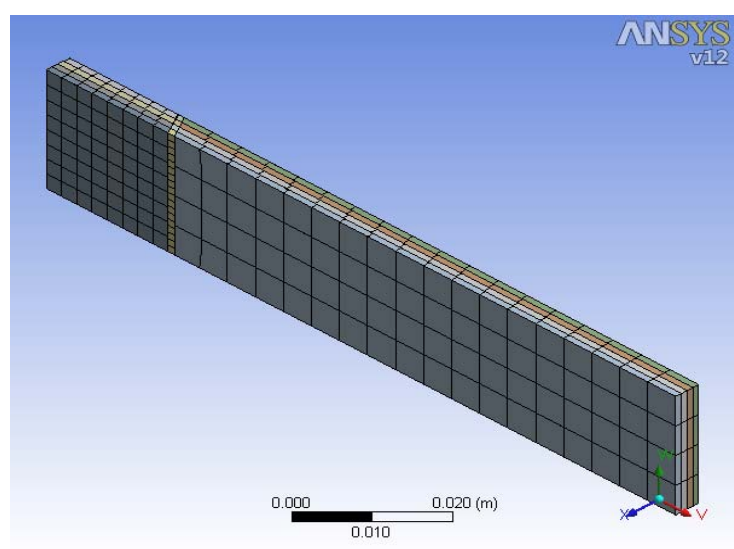

(a) FE model of the scarf repaired model(angle 60)

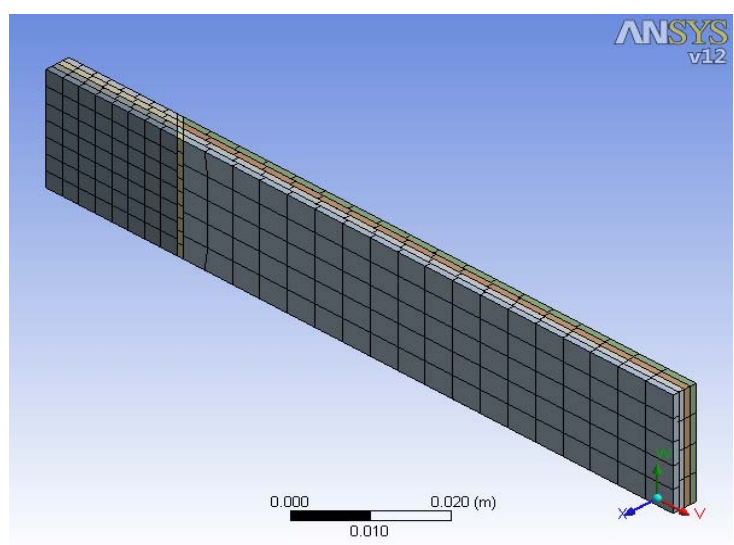

(b) FE model of the scarf repaired model(angle 45)

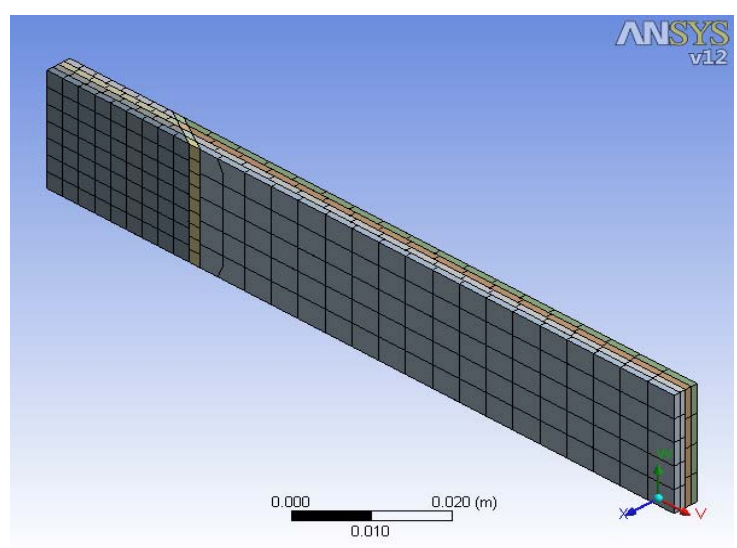

(c) FE model of the scarf repaired model(angle 30)

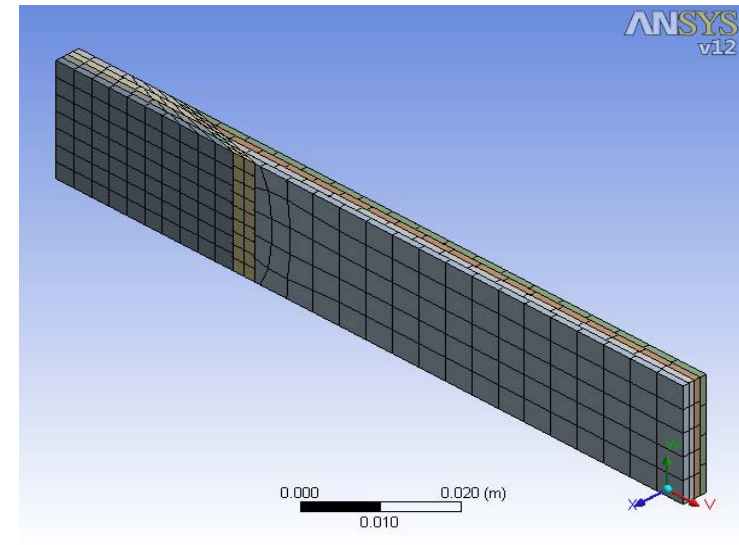

(d) FE model of the scarf repaired model(angle 15)

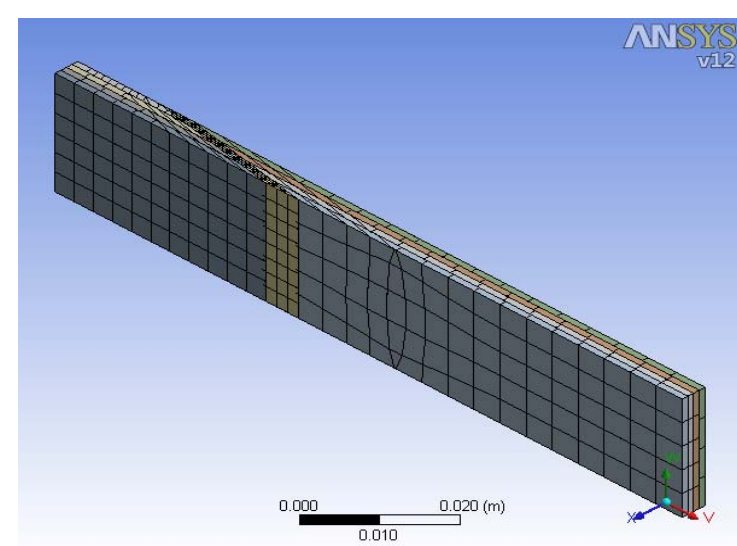

(e) FE model of the scarf repaired model(angle 10)

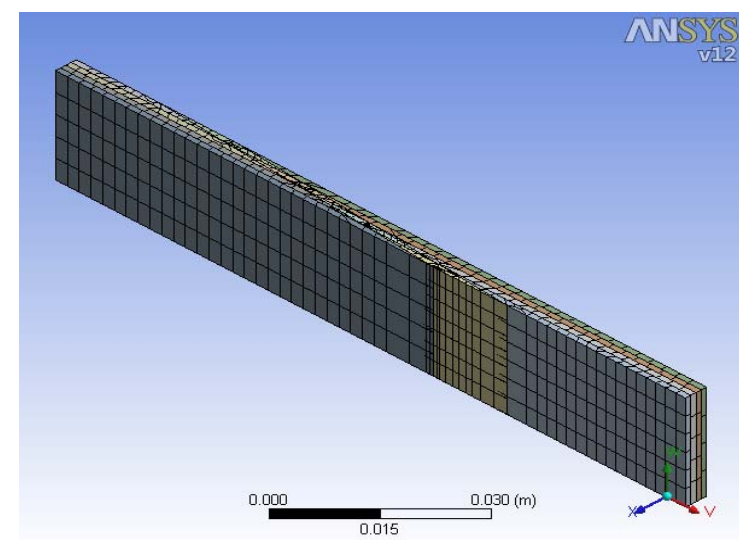

(f) FE model of the scarf repaired model(angle 5)

Fig. 1. Shows the FE models of the scarf sanding repair model 
Table 3. Number of elements and nodes

\begin{tabular}{c|c|c}
\hline \hline Scarf angle & Node & Element \\
\hline 60 & 5416 & 610 \\
45 & 5065 & 582 \\
30 & 5250 & 607 \\
15 & 5987 & 721 \\
10 & 7274 & 944 \\
5 & 13348 & 1815 \\
\hline
\end{tabular}

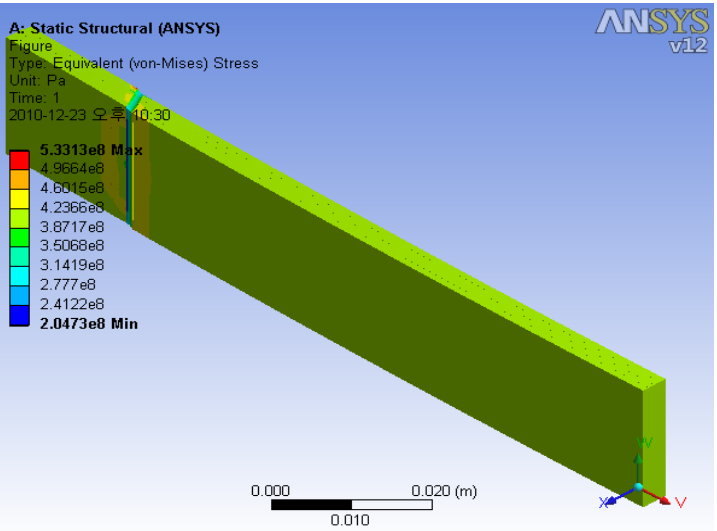

(a) Equivalent stress (angle 60)

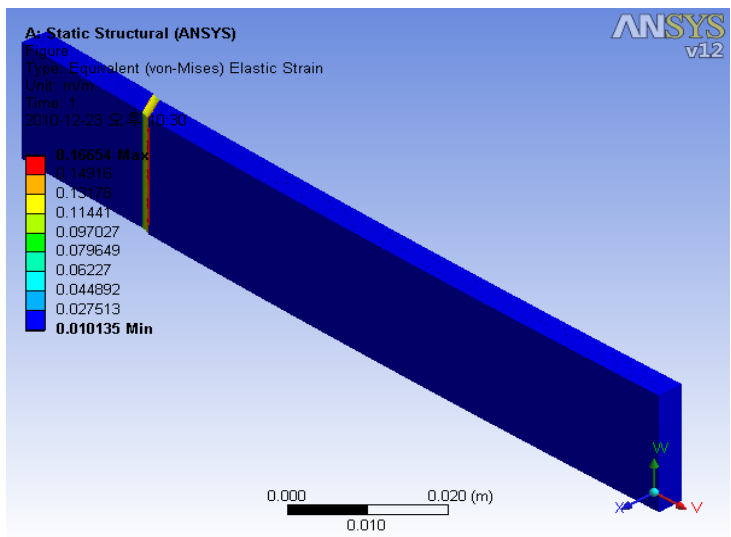

(b) Equivalent strain (angle 60)

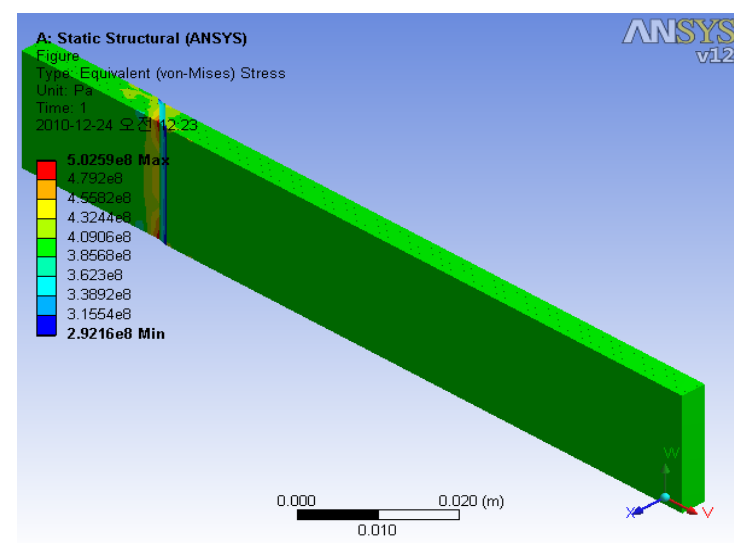

(c) Equivalent stress (angle 45)

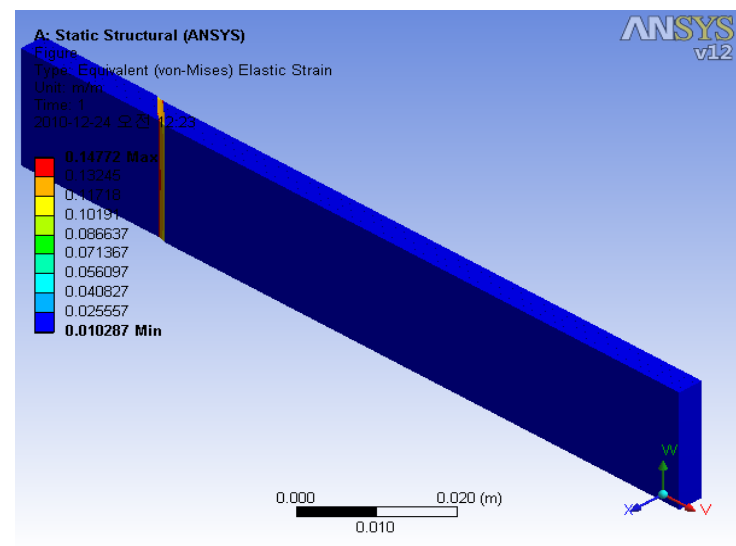

(d) Equivalent strain (angle 45)

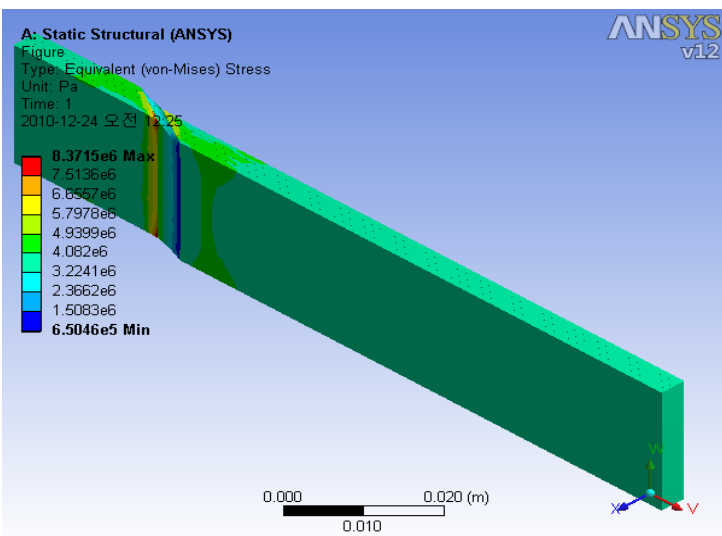

(e) Equivalent stress (angle 30) 


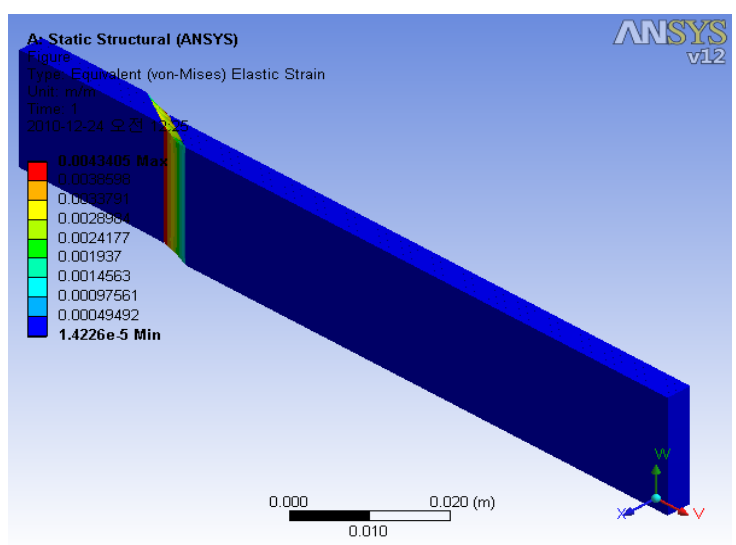

(f) Equivalent strain (angle 30)

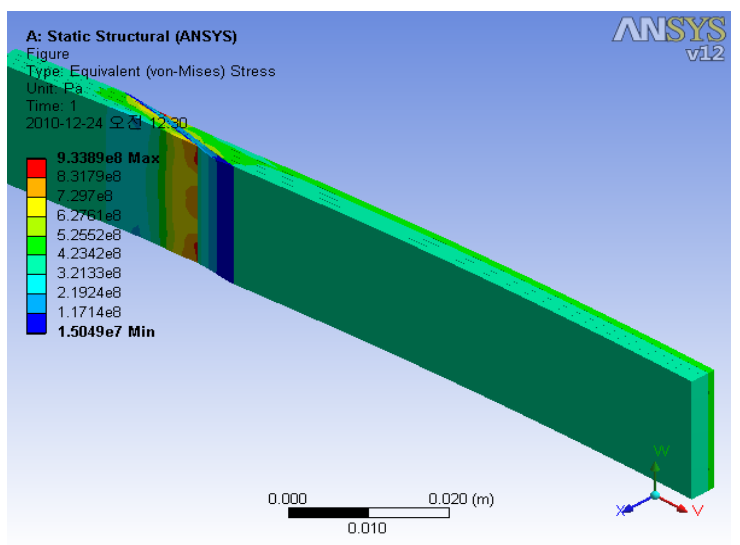

(g) Equivalent stress (angle 15)

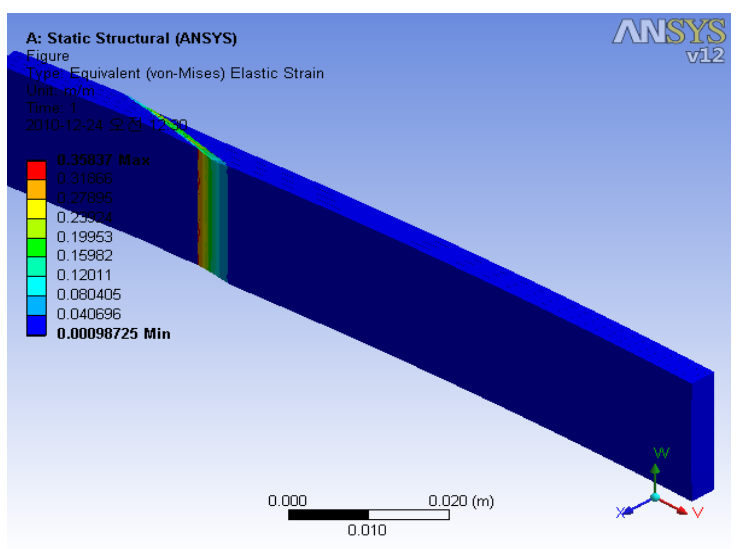

(h) Equivalent strain (angle 15)

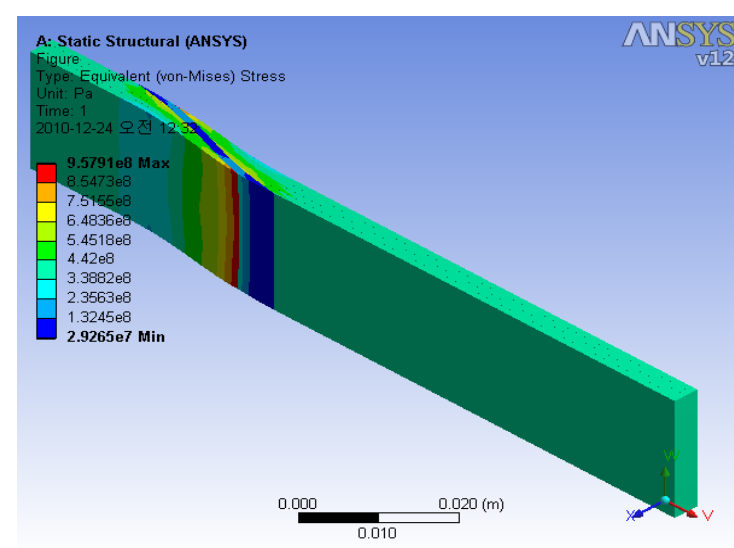

(i) Equivalent stress (angle 10)

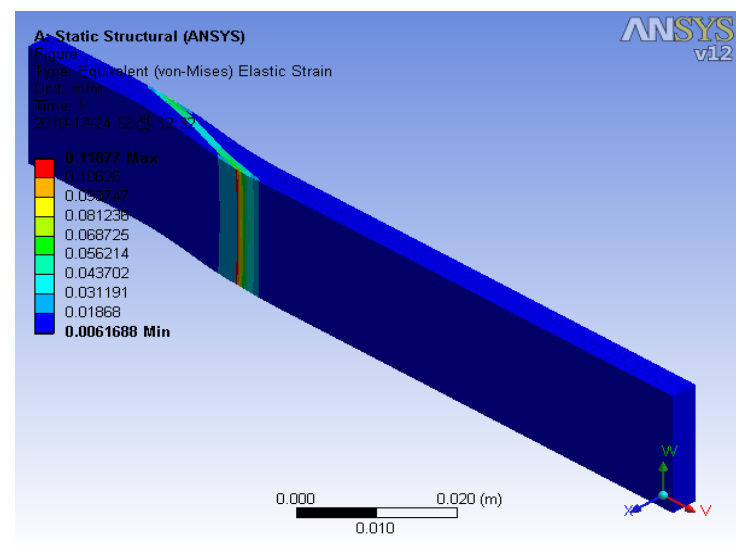

(j) Equivalent strain (angle 10)

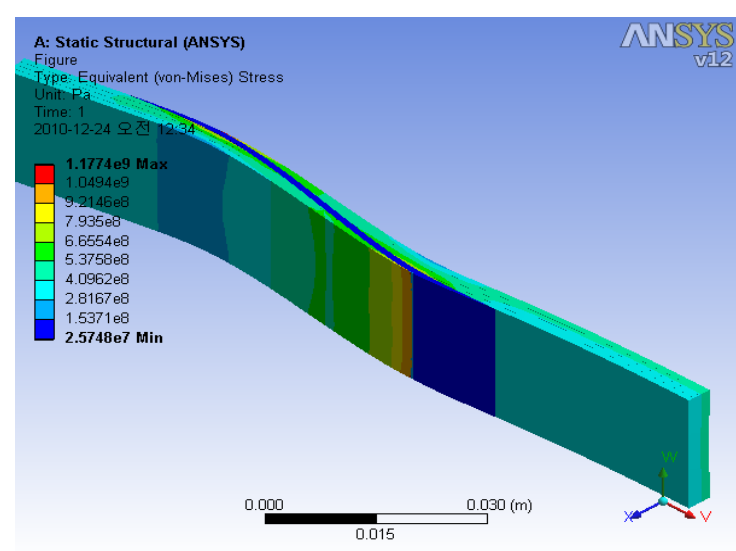

(k) Equivalent stress (angle 5) 


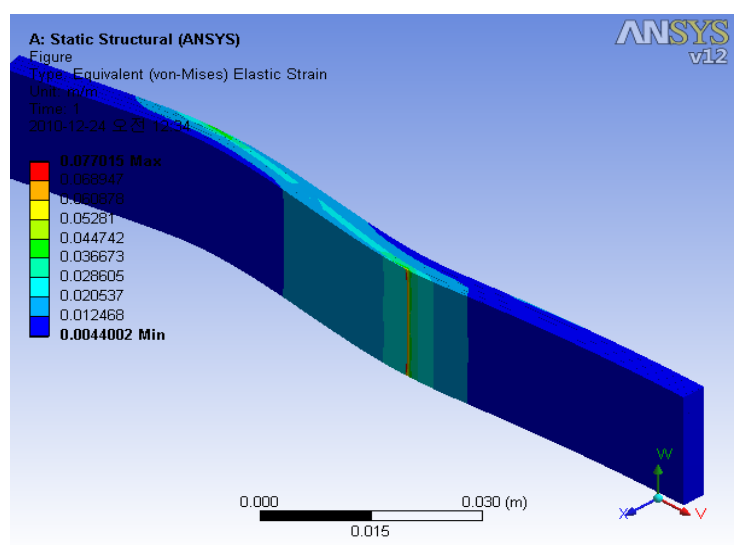

(l) Equivalent strain (angle 5)

Fig. 2. Stress and strain result of the FEM

A high scarf angle is an indication of the stress concentration. The load distribution with a scarf angle of $60^{\circ}$ and $45^{\circ}$ is similar to that of the patch repaired composites. The stress is concentrated on the scarf surface and works as a notch. This means that an applied stress is loaded onto the adhesive layer and at this time, the fracture strength is equal to that of the repair.

A low scarf angle indicates the stress distribution. A repaired structure with a scarf angle $<30^{\circ}$ it is ineffective; therefore, a repaired structure with a scarf angle of $5^{\circ}$ is the only effective case. The applied stress is loaded onto the laminate, where the fracture strength of the repaired structure will be similar to that of the mother laminate and the applied stress is distributed widely over the repaired area.

In addition, the stress is concentrated on the outside layer of the laminate, which means that an extra structural layer is needed to dissipate this stress.

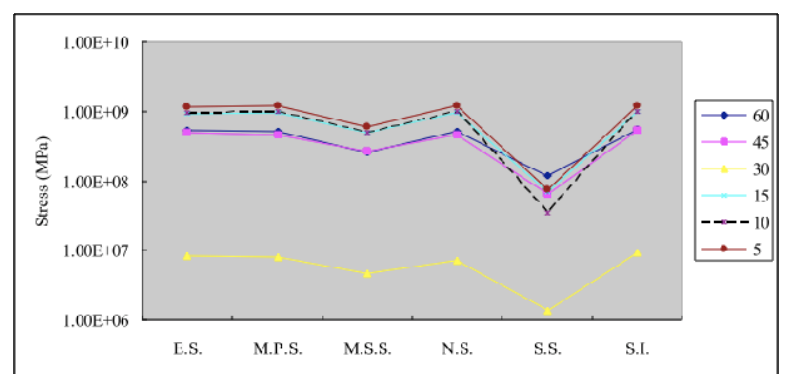

Fig. 3. Result of the FEM

The Tsai-Hill or Tai-Wu criteria were used for the composites. However, all the materials in this study were separated, with a single direction property considered; therefore Von-Mises stress was used. With the exception of $30^{\circ}$, the Von-Mises stress increased and the shear stress decreased with decreasing scarf angle. The Von-Mises stress was used for the fracture criteria, but can also be used for isotropic materials. Fig. 4 shows the normal stress divided by the shear stress rates (\%) as a function of the scarf angle.

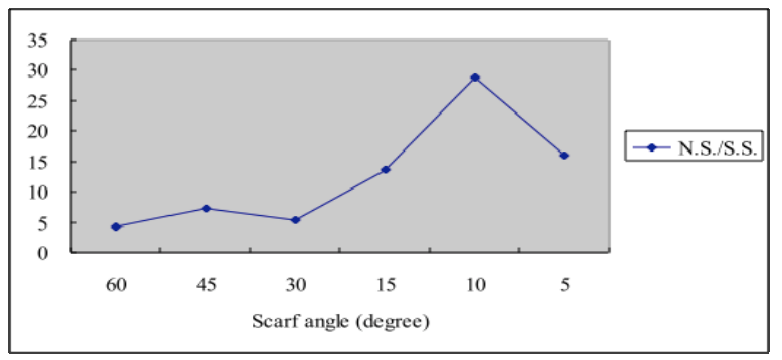

Fig. 4. Normal stress divided by the shear stress rate (\%) as a function of the scarf angle

\section{Conclusions}

This study examined the relationship between the scarf angle and stress distribution, and estimated the strength recovery using a finite element analysis. The following conclusions were drawn

1. Resin will fracture due to a tensile load if the scarf angle is high, which is similar to that with the patch repair method.

2. An applied stress can be loaded onto a repaired laminate if the scarf angle is $5^{\circ}$.

3. The Von-Mises stress increases with decreasing scarf angle.

4. With the exception of a scarf angle of $30^{\circ}$, the scarf angle can indicate the rates of shear and normal stresses.

Strength recovery will be better if the scarf angle is decreased to a lower angle. However, scarf machining requires more time, a high skill level and considerable expense. Therefore, a scarf angle of $5^{\circ}$ is the most effective for a repair.

These results may provide a guide for engineers wishing to formulate a standard for repair. The scarf angle needs to be carefully managed for a more efficient composite repair.

\section{Acknowledgments}

This research was financially supported by the Ministry of Education, Science Technology (MEST) and Korea Industrial Technology Foundation 
(KOTEF) through the Human Resource Training Project for Regional Innovation. Following are also results of a study on the "Human Resource Development Center for Economic Region Leading Industry" Project, supported by the Ministry of Education, Science \& Technology(MEST) and the National Research Foundation of Korea(NRF).

\section{References}

[1] D.G. Lee, "Reliable joining and repair technique on the composites.", Korean society of mechanical engineering, Vol. 44 No.6, pp.85-89, 2004

[2] George Marsh, "Airbus takes on Boeing with reinforced plastic A350 XWB”, Reinforced plastics, Vol.55 No.11, pp. 26-29, 2007

[3] G. Savage, "Formula 1 composites engineering", Engineering failure analysis, Vol.17 No.1, pp. 92115, 2010

[4] W.D. Kim, "Crack patching technique of aging aircraft using composite material", the Korean society for aeronautical \& space sciences, Proceeding of the Korean society for aeronautical \& space sciences, pp. 452-457, 1999

[5] Engr Sreejit Raghu, "Fiber reinforced polymer analysis and design, Ove arup \& partners international Ltd., 2009

[6] Stephan Hinz, "Damage characterization of fiber metal laminates under interlaminar shear load", Composites part A, Vol. 40, Elsevier, 2009 